\title{
Research on the Design Method of Energy- Saving Buildings Based on Digital Technology
}

\author{
Xiaobo Zheng \\ Xi'An Aeronautical University, Xi'an, Shaanxi, China
}

\begin{abstract}
The current social and economic development momentum is strong, and the social energy crisis is becoming increasingly serious. As an important link in energy consumption, the construction industry is shouldering an important mission of energy conservation. Guiding the design of energy-saving buildings with the concept of a full life cycle can effectively optimize the design process and achieve sustainable building development. Based on the life-cycle theory, the article summarizes the design principles and design methods of energy-saving buildings for the life-cycle, and aims to contribute a modest contribution to the sustainable development of China's construction industry.
\end{abstract}

KEYWORDS: Energy sasving buildings, Digital technology, Design model

\section{Introduction}

Due to the pursuit of higher profits and traditionally satisfying customers' price requirements and performance and quality, traditional building design has not considered environmental pollution and energy and resource consumption from the beginning of product design. Today, green energy conservation is the trend of the times, and it is also a requirement. Various energy-saving building designs are constantly emerging, and low-carbon buildings and energy-saving houses have become popular. The life cycle theory is derived from value engineering. We introduce it into the design of energy-saving buildings. With the help of various types of information related to the design object's entire life cycle, we use life cycle assessment, value analysis and system optimization to design. The completed design works have characteristics such as green.

2. The Necessity of Energy-Efficient Building Design for the Entire Life Cycle

Published by Francis Academic Press, UK 
Academic Journal of Computing \& Information Science

ISSN 2616-5775 Vol. 3, Issue 1: 96-101, DOI: 10.25236/AJCIS.2020.030110

At present, under the initiative of the state, "sustainable development" has become the development theme of many industries including construction. In the construction industry, "sustainable development" is inseparable from the rational allocation of resources and the strong protection of the environment, and energy-saving design. The life cycle contains the whole process of the emergence, development and demise of things. The whole life cycle of a building includes the entire process of production and mining of building materials, planning and scheme design, building construction and transportation, building maintenance operation and building demolition. The energy-saving building design for the whole life cycle is a design method that takes energy saving as the core and is in line with sustainable development and green ecology. Establishing the energy-saving awareness of the entire life cycle of the building, and infiltrating the concepts of energy conservation, emission reduction, environmental protection, and energy loss in the design stage can lay a solid foundation for the effective development of subsequent work and promote the sustainable development of the construction industry. Although the construction of modern buildings has greatly affected the environment and caused some damage to the natural ecology, the relationship between construction and environmental protection should not be opposite. Energy-saving design of buildings can bring the construction of modern buildings to the environment. Damage is minimized. In particular, the design of energy-saving buildings for the entire life cycle, because it involves the entire process of building from material production to demolition and recycling, can fundamentally make the building energy-saving and environmentally friendly, and to a certain extent play an active role in the effective development of environmental protection Promotion effect.

At present, energy-saving design is a very important issue facing the global construction industry. China's construction industry must recognize the importance of this issue. Through the effective development of energy-saving building design, design modern energy-saving buildings more in line with national standards. It is an important means for China's construction industry to become internationalized, an important opportunity to enhance the international status of China's construction industry, and an important measure to establish a good image for China's construction industry internationally. Today, with the continuous progress of modernization, energy crises have appeared in many regions of the world. As a country with a large population in the world, China has a large energy consumption and the energy crisis situation is very severe. Generally, in this case, the construction industry must effectively treat precious energy sources. Ground protection, through the design of energy-saving buildings throughout the life cycle, reduce the use of energy, enhance energy efficiency, and effectively alleviate the current energy crisis situation facing our country.

\section{The Combination of Life-Cycle Concepts and Energy-Efficient Buildings}

The so-called full life cycle process is mainly based on the consideration of the product life cycle, which should start from the basic design link, and comprehensively analyze the relevant factors of the comprehensive product planning

Published by Francis Academic Press, UK 
Academic Journal of Computing \& Information Science

ISSN 2616-5775 Vol. 3, Issue 1: 96-101, DOI: 10.25236/AJCIS.2020.030110

at the product design stage. The so-called energy-saving building refers to following the basic methods of climate design and energy saving, rationally planning the building, and finally designing a low-energy, green, and environmentally friendly building. Because the application of the whole life cycle theory has optimized the development process of the building from the initial design to the last use, the energysaving building design for the whole life cycle has great development prospects. The life cycle theory is applied to product design in terms of function and structure, not only covering design planning, production marketing, maintenance, etc., but also the final recycling aspect, which reflects the huge advantages of the combination of the two. The combination of the two needs to consider its evaluation standards and design principles. The evaluation of energy-saving buildings throughout the life cycle focuses on environmental and economic benefits. On the one hand, it can improve pollution reduction, save energy, and extend the service life; on the other hand, it can fully consider the life cycle cost and comprehensively balance the relationship between investment and investment. The principles of energy-efficient building design for the entire life cycle are mainly embodied in the functional and practical principle of building, the principle of technology first in building, the principle of environmental harmony in building, and the principle of economic rationality. Reasonably evaluate the design of energy-saving buildings throughout the life cycle and follow appropriate principles, and finally realize their maximum potential to achieve the development requirements of sustainable development strategies.

\section{Design Principles for Energy-Efficient Buildings for the Entire Life Cycle}

Although it is necessary to save resources in the design of the building, it is not the first priority of building design that save resources at the end. The building function is still the biggest premise of the design. Building functions such as basic building use functions, outdoor environmental performance, and architectural aesthetic effects should be given priority, convenient and practical, energy saving and emission reduction. This is the core of energy-saving building design throughout the life cycle. The principle of technological advancement Energy-saving building design for the entire life cycle cannot be separated from advanced technology. The technological advancement should be penetrated into each stage of the building's entire life cycle. Adopting appropriate science and technology according to the different stages of the building can ensure that the various functions of the building are efficiently performed, so that the building can operate smoothly from the initial use to the end of the building life, and fully reflect the energy saving characteristics. 2.3 Environmental coordination principle Energy saving, emission reduction, and resource saving are based on the harmony between man and nature. Buildings must be harmonious with the environment. The following design principles should be observed in specific operations: (1) Reduce energy consumption. On the one hand, designers should try to use renewable energy sources such as solar energy, wind energy, geothermal energy, etc., and use non-renewable energy sources to a limited extent; on the other hand, rationally allocate resources and use scientific energysaving technologies for non-renewable energy sources that must be used. Improve the

Published by Francis Academic Press, UK 
Academic Journal of Computing \& Information Science

ISSN 2616-5775 Vol. 3, Issue 1: 96-101, DOI: 10.25236/AJCIS.2020.030110

energy efficiency of the building's entire life cycle and reduce energy consumption. (2) Reduce environmental pressure. Attention should be paid to reducing the environmental damage caused by construction waste, domestic waste, and solid, gas, and liquid pollutants during the construction and use of buildings. The effective use of waste treatment systems should be run through all stages of the building's life cycle to reduce the environment. The purpose of pressure; (3) choose green safety materials. In the selection of construction materials, safety must be the first priority. Construction materials should be selected from pollution-free, safe and hygienic green environmental protection construction materials to ensure that building builders and users can enjoy a healthy, comfortable, green and energy-saving environment during the entire life cycle of the building. Work and life.

Energy-saving building design for the entire life cycle requires designers to fully consider building costs while following the above three principles. Realize the necessary functions of the building with the lowest construction cost, and minimize the economic cost of the life cycle (including all the costs required for the construction and maintenance of the building in each stage of the building's entire life cycle).

\section{Energy-Efficient Building Design for the Entire Life Cycle}

The procedures for the design of energy-saving buildings throughout the life cycle mainly include determining design goals, preliminary plan ideas, alternative design, life cycle evaluation, analysis and improvement, and determining the best scheme. Interactive information. The first is to determine the design goals. The determination of design goals is to ensure that the building has the four basic characteristics of energy saving, sustainable development, ecology and greening throughout its life cycle, and then formulate corresponding goals according to different types of buildings. To achieve the goals described above and determine Reasonable system boundaries. How to determine a reliable and reasonable design goal requires the designer to have rich experience, to conduct on-site inspections and calculate costs on the basis of familiarity with customer needs, to achieve a balance between environmental and economic benefits, not only to ensure sustainable energy saving requirements, but also to ensure Consumer rights.

The second is the preliminary program idea. Based on the well-defined design goals, we use functional analysis and creative thinking to conceive a number of preliminary schemes. The preliminary plan does not need to be limited by too many constraints, and the focus is to get a variety of design options to choose from. The design of energy-saving buildings for the whole life cycle needs to consider cost accounting and risk assessment from beginning to end. Although the initial scheme concept may produce many unreasonable concepts, the introduction of a good quality and safety risk assessment and management system can be constrained the designer determines the goal within a reasonable range. The third is alternative design. The choice of alternatives is to adopt certain technical measures on the basis of following the energy-saving design guidelines, to clarify the idea, and to understand the raw

Published by Francis Academic Press, UK 
Academic Journal of Computing \& Information Science

ISSN 2616-5775 Vol. 3, Issue 1: 96-101, DOI: 10.25236/AJCIS.2020.030110

material procurement, equipment selection, and scheme construction to achieve the preliminary scheme. At the same time, the preliminary construction scheme must be as soon as possible Determined to provide a strong guarantee for the normal operation of the next step. The alternatives are not limited to one, but may be multiple in order to provide support when the preferred solution encounters difficulties. The fourth is life cycle assessment. Through systematic analysis of the scheme and comprehensive design concepts, we have obtained preliminary optimized alternatives. We need to comprehensively evaluate the design scheme to examine its practicability. Although the theory can only be used as a reference relative to practice, excellent design scheme evaluation can effectively avoid extreme problems and sudden problems in practice. Among them, life cycle assessment is the most powerful method to solve this problem. It mainly includes inventory analysis. And impact analysis. Finally, analyze and improve to determine the best solution. Based on the analysis and evaluation results of life cycle assessment, feedback and improvement of the original plan, find problems, find the most prone risks in the design process, and further optimize to make the plan more reasonable and complete, and finally achieve the most optimal life-cycle energy-saving building design. Best plan.

\section{Conclusion}

The development of energy-efficient building design has a long way to go. The full life cycle assessment can help people to change the disadvantages of the value system and ideology. Therefore, the energy-saving building design oriented to the entire life cycle is an effective advanced idea of the sustainable development strategy A successful case combining traditional design, this design method enables architects to formulate, revise and improve design solutions through modern thinking methods of rigorous reasoning and quantitative evaluation. The disadvantages of the onesidedness and uncertainty of the traditional scheme can be reduced or even avoided through the evaluation of the life cycle, and the resulting energy-saving building design also tends to be more scientific and systematic. The scientific design scheme has a strong theoretical basis, and the systematic design scheme has a rich background to support it.

\section{References}

[1] Chen Yan(2015). Research on Energy-saving Building Design Method Based on the Whole Life Cycle. Building Materials Decoration, no. 8, pp. 99-99.

[2] Wang Yongqun(2017). Research on Design Methods of Energy-saving Buildings Facing the Whole Life Cycle. Housing and Real Estate, no.15, pp. $215+235$.

[3] Ma Zhihong(2014). Research on design method of energy-saving building oriented to the whole life cycle. Sichuan Cement, no.10, pp. 87-89.

[4] Jiang Wenzhong(2015). Research on energy-saving building design method based on full life cycle. Building Materials and Decoration, no.38,p.116

Published by Francis Academic Press, UK 
Academic Journal of Computing \& Information Science

ISSN 2616-5775 Vol. 3, Issue 1: 96-101, DOI: 10.25236/AJCIS.2020.030110

[5] Zhen Lanping, Wu Huixin(2003). Research on the design method of energysaving buildings oriented to the whole life cycle. Journal of Architecture, no.3, pp. 56-57.

[6] Su Ke(2017). Research on Design Methods of Energy-saving Buildings Oriented to the Whole Life Cycle. China Science and Technology Investment, no. 22, p.89

Published by Francis Academic Press, UK

-101 - 